\title{
Momentum effects in the cryptocurrency market after one-day abnormal returns
}

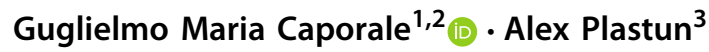

Published online: 27 May 2020

(c) The Author(s) 2020

\begin{abstract}
This paper examines whether there exists a momentum effect after one-day abnormal returns in the cryptocurrency market. For this purpose, a number of hypotheses of interest are tested for the Bitcoin, Ethereum and Litecoin exchange rates vis-à-vis the US dollar over the period 01.01.2015-01.09.2019, specifically whether or not: (H1) the intraday behavior of hourly returns is different on abnormal days compared to normal days; (H2) there is a momentum effect on days with abnormal returns, and (H3) after one-day abnormal returns. The methods used for the analysis include various statistical methods as well as a trading simulation approach. The results suggest that hourly returns during the day of positive/negative abnormal returns are significantly higher/lower than those during the average positive/negative day. The presence of abnormal returns can usually be detected before the day ends by estimating specific timing parameters. Prices tend to move in the direction of the abnormal returns till the end of the day when it occurs, which implies the existence of a momentum effect on that day giving rise to exploitable profit opportunities. This effect (together with profit opportunities) is also observed on the following day. In two cases (BTCUSD positive abnormal returns and ETHUSD negative abnormal returns), a contrarian effect is detected instead.
\end{abstract}

Keywords Cryptocurrency · Anomalies · Momentum effect · Abnormal returns · Patterns

Electronic supplementary material The online version of this article (https://doi.org/10.1007/s11408-02 0-00357-1) contains supplementary material, which is available to authorized users.

$\bowtie$ Guglielmo Maria Caporale

Guglielmo-Maria.Caporale@brunel.ac.uk

Alex Plastun

o.plastun@uabs.sumdu.edu.ua

1 Department of Economics and Finance, Brunel University, London UB8 3PH, UK

2 CESifo and DIW Berlin, Berlin, Germany

3 Department of International Economic Relations, Sumy State University, Sumy, Ukraine 
JEL Classification G12 · G17 · C63

\section{Introduction}

It is well known that the efficient-market hypothesis (EMH) is inconsistent with the existence of abnormal returns, i.e., of fat tails in the price distribution. However, numerous empirical studies have reported evidence of so-called market overreactions. De Bondt and Thaler (1985) developed the overreaction hypothesis to describe price patterns caused by abnormal price changes. The subsequent literature has also analyzed the reasons for abnormal price changes (Griffin and Tversky 1992; Aiyagari and Gertler 1999; Madura and Richie 2004; Mynhardt and Plastun 2013); price patterns (Cutler et al. 1991; Ferri and Min 1996); trading strategies based on overreactions (Jegadeesh and Titman 1993; Caporale and Plastun 2019); the influence of price overreactions on market participants (Savor 2012), etc. According to the overreaction hypothesis, there should be price reversals after abnormal price changes and most empirical studies (De Bondt and Thaler 1985; Jegadeesh and Titman 1993; Ferri and Min 1996; Lobe and Rieks 2010; Mynhardt and Plastun 2013; Caporale et al. 2018) have provided evidence of such reversals. However, some papers detect momentum effects instead (Cox and Peterson 1994).

The cryptocurrency market represents a particularly interesting case being rather new, relatively unexplored and at the same time extremely vulnerable to abnormal returns, given its high volatility relative to the FOREX, stock and commodity markets, etc. (Cheung et al. 2015; Aalborg et al. 2019; Caporale and Plastun 2019). A number of recent studies analyze momentum and contrarian effects in this market (Caporale and Plastun 2019; Kosc et al. 2019; Panagiotis et al. 2019; Qing et al. 2019; Yukun and Tsyvinski 2019) and obtain mixed results.

The present paper extends the analysis of Caporale and Plastun (2019) by examining whether there exists a momentum effect after one-day abnormal returns in the cryptocurrency market. For this purpose, a number of hypotheses of interest are tested for the Bitcoin, Ethereum and Litecoin exchange rates vis-à-vis the US dollar over the period 01.01.2015-01.09.2019, specifically whether or not: (H1) the intraday behavior of hourly returns is different on abnormal returns days compared to normal days; (H2) there is a momentum effect on abnormal returns days, and (H3) after one-day abnormal returns. The methods used for the analysis include statistical tests and the cumulative abnormal returns and trading simulation approaches.

The results suggest the presence of strong momentum effect on days with abnormal price changes and the day after. By specifying timing parameters for these effects, it is possible to design profitable trading strategies based on the detected anomalies. Their presence in a market normally considered one of the most efficient is a very interesting finding. Future research could examine the same issue in other markets such as stock markets, FOREX and commodity markets.

Our findings are relevant to both academics interested in the validity of the efficientmarket hypothesis (EMH) and practitioners (traders, investors, financial analysts, etc.) aiming to design profitable trading strategies based on the possible existence of momentum effects, the timing of abnormal returns and the duration of the anomaly. 
The remainder of the paper is organized as follows: Section 2 reviews the relevant literature. Section 3 describes the methodology. Section 4 discusses the empirical results. Section 5 offers some concluding remarks.

\section{Literature review}

The seminal study on market overreactions by De Bondt and Thaler (1985) showed that the best (worst) performing portfolios in the NYSE over a 3-year period tended to under (over)-perform over the following 3-year period, which resulted in significant deviations of asset prices from their fundamental values and consequent price corrections. A specific case of overreaction concerns price behavior after days with abnormal returns (large positive and negative returns during that day).

Abnormal returns can be the result of herd effects (Griffin and Tversky 1992; Madura and Richie 2004), the behavior of "noise" traders (Aiyagari and Gertler 1999; Hong and Stein 1999), different cognitive traps and biases such as overconfidence and other behavioral patterns (Barberis et al. 1998; Daniel et al. 1998), low liquidity (Jegadeesh and Titman 1993), macroeconomic announcements (Kocenda and Moravcová 2018), and the use of technical analysis for making investment decisions (Duran and Caginalp 2007).

Further studies (Jegadeesh and Titman 1993; Ferri and Min 1996; Poteshman 2001; Lobe and Rieks 2010) analyzed abnormal returns in different markets, assets, periods, data frequencies and reached similar conclusions, namely that there are price reversals after abnormal price changes (Bremer and Sweeny 1991; Clare and Thomas 1995; Giannetti et al. 2006; Mynhardt and Plastun 2013; Caporale et al. 2018). Price reversals after abnormal returns are detected in different stock markets: USA (Brown et al. 1988; Larson and Madura 2003; Clements et al. 2009), Japanese (Chang et al. 1995), Canadian (Kryzanowski and Zhang 1992), Ukrainian (Mynhardt and Plastun 2013), and many others. Abnormal returns and specific price patterns have also been found in the FOREX (Caporale et al. 2018), option (Poteshman 2001) and commodity markets (Cutler et al. 1991).

Papers examining abnormal returns can be divided into different categories: those exploring the reasons for abnormal price changes (Griffin and Tversky 1992; Aiyagari and Gertler 1999; Madura and Richie 2004; Mynhardt and Plastun 2013); those focusing on detecting price patterns (Cutler et al. 1991; Ferri and Min 1996); those investigating the effects of abnormal returns on market participants (Savor 2012), and those analyzing trading strategies based on abnormal returns (Jegadeesh and Titman 1993; Caporale and Plastun 2019).

Wan and Kao (2009) explored contrarian trading in the FOREX and find evidence of efficiency for the GBPJPY exchange rate. One-day abnormal returns and the patterns they generate were investigated by Parikakis and Syriopoulos (2008), who concluded that a contrarian strategy is profitable in the FOREX. Brown et al. (1988) found evidence of a contrarian effect after large price movements in the US stock market. Ferri and Min (1996) confirmed the presence of a contrarian effect in the S\&P 500 over the period 1962-1991. By contrast, Cox and Peterson (1994) did not find a negative correlation between abnormal returns on the day prices fall and the following three days. Schnusenberg and Madura (2001) and Lasfer et al. (2003) provided evidence of 
a momentum effect. Savor (2012) and Govindaraj et al. (2014) found both effects in the US stock market. On the whole, the evidence is mixed, which reflects differences in data sets, methodology, etc.

As for the practical implications of price patterns resulting from abnormal returns, Pritamani and Singal (2001) showed that information about large price changes can be used to design profitable trading strategies. Jegadeesh and Titman (1993) developed a contrarian trading strategy at a monthly frequency; they found that such a strategy generates a $12 \%$ profit per year. A similar strategy, but at a weekly frequency, was developed by Lehmann (1990) and was found to be equally profitable. Baytas and Cakiki (1999) showed that contrarian portfolios on the long-term horizons can generate significant profits. Caporale et al. (2018) demonstrated that a strategy based on countermovements after one-day abnormal returns does not generate profits in the FOREX and the commodity markets, but it is profitable in the case of the US stock market. Parikakis and Syriopoulos (2008) investigated patterns following excess one-day fluctuations for various currencies and found that a contrarian strategy is profitable in the FOREX. Cox and Peterson (1994) concluded that a trading strategy based on stock market abnormal returns is not profitable, especially in the presence of trading costs.

Concerning the relatively new cryptocurrency market, several studies have analyzed its efficiency (Bartos 2015; Urquhart 2016), long-memory properties and persistence (Bariviera 2017), the existence of price bubbles (Corbet et al. 2018), its competitiveness (Halaburda and Gandal 2014), the issue of predictability (Bouri et al. 2018; Caporale et al. 2019) and the presence of anomalies (Kurihara and Fukushima 2017; Caporale and Plastun 2018). However, there are very few studies focusing on abnormal returns in the cryptocurrency market. Chevapatrakul and Mascia (2019) using the quantile autoregressive model showed that days with extremely negative returns are likely to be followed by periods characterized by negative returns and weekly positive returns as Bitcoin prices continue to rise. Caporale and Plastun (2019) found evidence of price patterns after one-day abnormal returns, i.e., the next-day price changes in both directions are bigger than after "normal" days; they showed that a strategy based on the momentum effect (rather than counter-movements) after abnormal returns is profitable.

Qing et al. (2019) using DFA and MF-DFA analysis found a strong momentum effect in BTC and ETH price behavior, and a reversion effect in XRP and EOS prices after abnormal returns. Kosc et al. (2019) investigated investment strategies in the cryptocurrency market and reported a clear and significant dominance of the short-term contrarian effect over momentum effect. Panagiotis et al. (2019) identified momentum effects in the cryptocurrency market; these are highly significant for short-term portfolios but less so in the long run. Yukun and Tsyvinski (2019) also found a strong momentum effect in this market.

To sum up, there is no consensus in the academic literature about the possible presence of momentum effects after one-day abnormal returns. There is also lack of evidence concerning price behavior during days characterized by abnormal returns and whether or not specific price patterns appear on those days. To address these issues, the following hypotheses will be tested in this paper: (H1) the intraday behavior of hourly returns is different on abnormal days compared to normal days; (H2) there is a momentum effect on days with abnormal returns, and (H3) after one-day abnormal 
returns. The analysis will be carried out for the cryptocurrency market using a variety of methods as detailed below.

\section{Methodology}

Our sample includes daily and hourly data for the following cryptocurrencies: Bitcoin, Ethereum and Litecoin. We select Bitcoin, Ethereum and Litecoin because they are the cryptocurrencies with the highest market capitalization and longest time horizon, as shown by the data from CoinMarketCap accessed on October 8, 2019. We analyze their exchange rates vis-à-vis the US dollar: BTCUSD, ETHUSD and LTCUSD. The sample period is 01.01.2015-01.09.2019, and the data sources are CoinMarketCap (https://coinmarketcap.com/coins/), Gemini (https://gemini.com/) and Bitstamp (https://www.bitstamp.net). These are leading exchanges and trading platforms in the cryptocurrency market. For example, CoinMarketCap calculates prices as the volumeweighted average of all prices reported for each market. As a result, Bitcoin prices are the average of those from 400 markets.

A key issue is the definition of abnormal returns. There are two different approaches: the dynamic trigger one, which is based on relative values (usually the number of standard deviations added to the average), and the static one (which uses actual price changes as an overreaction criterion). Caporale and Plastun (2019) analyzed the suitability of these methods for the cryptocurrency market and concluded that the dynamic trigger approach is preferable. Consequently, we use it in this paper.

In order to avoid the distortions caused by price gaps, returns $\left(R_{i}\right)$ are computed as follows:

$$
R_{i}=\left(\frac{\text { Close }_{i}}{\text { Open }_{i}}-1\right) \times 100 \%,
$$

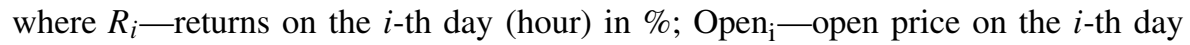
(hour); Close $\mathrm{i}_{\mathrm{i}}$-close price on the $i$-th day (hour).

The returns calculated using (1) are divided into two data sets corresponding, respectively, to positive and negative abnormal returns with the aim of testing for possible differences in price behavior between those two cases.

A positive abnormal return is defined as follows:

$$
R_{i}>\left(\bar{R}_{n}+k \times \delta_{n}\right)
$$

and a negative abnormal return as:

$$
R_{i}<\left(\bar{R}_{n}-k \times \delta_{n}\right)
$$

where $k$ is the number of standard deviations used to identify the abnormal returns $(k=$ 2 for BTCUSD and $k=1.5$ for ETHUSD and LTCUSD, $k$ being chosen on the basis of the sample size to generate in each case a sufficient number of detected abnormal returns); $\bar{R}_{n}$ is the average size of daily returns for period $n$ 


$$
\bar{R}_{n}=\sum_{i=1}^{n} R_{i} / n
$$

and $\delta_{n}$ is the standard deviation of daily returns for period $\mathrm{n}$

$$
\delta_{n}=\sqrt{\frac{1}{n} \sum_{i=1}^{n}\left(R_{i}-\bar{R}\right)^{2}} .
$$

To test the hypotheses of interest, we use the following methods:

- Visual inspection and average analysis;

- Student's $t$ tests;

- A cumulative abnormal returns approach;

- A trading simulation approach.

The cumulative abnormal returns approach is based on MacKinlay and Richardson (1997) and is standard for event studies. Abnormal returns are defined as follows:

$$
A R_{t}=R_{t}-E\left(R_{t}\right)
$$

where $R_{t}$ is the return at time $t$ and $E\left(R_{t}\right)$ is the corresponding average return computed over the whole sample period as follows:

$$
E\left(R_{t}\right)=\left(\frac{1}{T}\right) \sum_{i=1}^{T} R_{i},
$$

where $T$ is the sample size.

The cumulative abnormal return denoted as $C A R_{i}$ is simply the sum of the abnormal returns:

$$
C A R_{i}=\sum_{i=1}^{24} A R_{i},
$$

where $i$ starts with 1 (the first hour of the trading day) and ends with 24 (the last hour of the trading day). A day consists of $24 \mathrm{~h}$.

Parametric $t$ tests are also carried out for Hypothesis 1. The Null Hypothesis (H0) is that the data (hourly returns on the overreaction day and in the full sample) belong to the same population, a rejection of the null suggesting the presence of a statistical anomaly in the price behavior on the abnormal returns day. The test is carried out at the $95 \%$ confidence level, and the degrees of freedom are $N-1$ ( $N$ being equal to $N 1$ $+N 2)$.

The trading simulation approach replicates the actions of traders by using appropriate algorithms for trading strategies based on the observed price patterns; its aim is to establish whether the detected anomalies can be exploited to generate abnormal profits. It should be mentioned that our analysis does not incorporate transaction costs 
Table $1 t$ test for evaluating the success of the trading strategy: LTCUSD, positive abnormal returns, Strategy 1

\begin{tabular}{ll}
\hline Parameter & Value \\
\hline Number of trades & 38 \\
Total profit & $311.39 \%$ \\
Average profit per trade & $8.19 \%$ \\
Standard deviation & $7.01 \%$ \\
$t$ test & 7.20 \\
$t$ critical value $(0.95 \%)$ & 1.78 \\
Null hypothesis & Rejected
\end{tabular}

This table presents the results of the $t$ test for evaluating the success of the trading strategy. The first column specifies the parameters, and the second shows the results for the case: LTCUSD, positive abnormal returns, Strategy 1

such as spreads, broker or bank fees and swaps and therefore is only a proxy for actual trading. However, in the case of Internet trading, such costs are typically small and ignoring them does not affect the results.

The percentage results for an individual deal are computed as follows:

$$
\% \text { result }=\left(\frac{P_{\text {close }}}{P_{\text {open }}}-1\right) \times 100 \%,
$$

where $P_{\text {open }}$-opening price for the trade, $P_{\text {close }}$-closing price for the trade.

The sum of the results from each trade is the total financial result of trading. A strategy producing positive total profits implies that there exists an exploitable market anomaly.

Another important indicator of the degree of success of the trading strategy is the percentage of successful trades:

$$
\% \text { successful trades }=\frac{100 \% \times \text { number of successful trades }}{\text { overall number of trades }} .
$$

To establish whether or not the results obtained are statistically different from the random trading ones, $t$ tests are carried out. These compare the means from two samples to see whether or not they come from the same population. The first sample consists of the trading results from the trading strategy, and the second one of random trading results. The null hypothesis is that the mean is the same in both samples, and the alternative that it is not. The computed values of the $t$ test are compared with the critical ones at the 5\% significance level. Failure to reject the null implies that there are no advantages from exploiting the respective trading strategy since the trading results do not differ from the random ones, while a rejection suggests that the adopted strategy can generate abnormal profits since the trading results are not random and therefore, it is possible to "beat the market." As an example, the $t$ test results for LTCUSD in the case of Strategy 1 are shown in Table 1. 


\section{Empirical results}

We divide the results into two sets including, respectively, those for the day of abnormal returns and those for the day after in order to explore price behavior when abnormal price movements are observed and after them. The results for BTCUSD for the day of abnormal returns and the day after are presented in Appendices A and B (available in a supplementary file). Figures A.1 and A.2 show that returns on abnormal returns days differ from those on normal days; the $t$ test statistics confirm that these differences are statistically significant. This holds for both positive and negative abnormal returns (Table A.2 and Table A.3).

The cumulative abnormal returns analysis (Table A.4 and Figure A.3) provides information on the average timing of the anomaly appearance: in general, positive abnormal return are detected after $6 \mathrm{pm}$ and negative ones after $4 \mathrm{pm}$, namely in both cases some time before the end of the trading day.

Concerning price behavior on the day after abnormal returns, average hourly BTCUSD returns after a positive abnormal return are much lower than on normal days during the first hours of the following day (Figure B.1), and these differences are statistically significant (Table B.1), which implies the existence of a contrarian effect. As for negative abnormal returns, on the following day prices tend to move in the direction of the abnormal returns (Figure B.2 and Table B.2), which represents evidence of a momentum effect.

Specific timings for trading can be determined. The contrarian strategy for BTCUSD after a positive abnormal return is as follows: sell on the start of the day and close position after $4 \mathrm{pm}$. The momentum strategy for the case of negative abnormal return is instead to sell at the start of the day after the negative abnormal returns and close this position after $11 \mathrm{am}$ (Table B.3 and Figure B.3).

A similar analysis is carried out for LTCUSD (Appendices C and D) and ETHUSD (Appendices E and F).

Figures C.1 and C.2 (for the case of LTCUSD) as well as Figures E.1 and E.2 (for the case of ETHUSD) show that returns on abnormal returns days are higher than those on normal days. These differences are statistically significant in most cases for both positive and negative abnormal returns (Tables C.2-C.3 for the case of LTCUSD and Tables E.2-E.3 for the case of ETHUSD).

To detect possible price patterns on the day of the abnormal returns a cumulative abnormal returns analysis is carried out. The price of LTCUSD (Table C.4 and Figure C.3) and ETHUSD (Table E.4 and Figure E.3), respectively, tends to move in the direction of the abnormal return till the end of the day; in most cases, positive abnormal returns appear after $1.00 \mathrm{pm}$ (LTCUSD) and $12.00 \mathrm{pm}$ (ETHUSD); for the negative ones, timing parameters are as follows: $2.00 \mathrm{pm}$ (LTCUSD) and $1.00 \mathrm{pm}$ (ETHUSD).

The price behavior on the day after abnormal returns for both LTCUSD (Figure D.3 and Table D.3) and ETHUSD (Figure F.3 and Table F.3) is not consistent with the overreaction hypothesis, since during the first half of the day prices tend to move in the direction of the abnormal returns. This is true of both positive and negative abnormal returns. The only exception is the price behavior of ETHUSD in the case of negative overreactions (Table F.3). 
Table 2 Overall results for the case of positive abnormal returns

\begin{tabular}{|c|c|c|c|}
\hline Parameter/instrument & BTCUSD & LTCUSD & ETHUSD \\
\hline \multicolumn{4}{|c|}{ Day of the abnormal returns } \\
\hline $\begin{array}{l}\text { Are there significant } \\
\text { differences in returns } \\
\text { (abnormal day vs } \\
\text { usual day)? }\end{array}$ & Yes & Yes & Yes \\
\hline $\begin{array}{l}\text { Are there any patterns } \\
\text { in cumulative } \\
\text { abnormal returns } \\
\text { dynamics? }\end{array}$ & $\begin{array}{l}\text { Yes. CAR increase till } \\
\text { the end of the day }\end{array}$ & $\begin{array}{l}\text { Yes. CAR increase till } \\
\text { the end of the day }\end{array}$ & $\begin{array}{l}\text { Yes. CAR increase till } \\
\text { the end of the day }\end{array}$ \\
\hline $\begin{array}{l}\text { Timing of abnormal } \\
\text { returns }\end{array}$ & 18:00 & 13:00 & 12:00 \\
\hline \multicolumn{4}{|c|}{ Day after the abnormal returns } \\
\hline $\begin{array}{l}\text { Is there momentum } \\
\text { effect on the day } \\
\text { after the abnormal } \\
\text { returns? }\end{array}$ & No & Yes & Yes \\
\hline $\begin{array}{l}\text { Timing parameters of } \\
\text { momentum } \\
\text { movements }\end{array}$ & $\begin{array}{l}\text { Since the start of the } \\
\text { day till } 16: 00 *\end{array}$ & $\begin{array}{l}\text { Since the start of the } \\
\text { day till 13:00 }\end{array}$ & $\begin{array}{l}\text { Since the start of the } \\
\text { day till 21:00 }\end{array}$ \\
\hline
\end{tabular}

This table presents the overall results for the case of positive abnormal returns. The first column reports the considered parameters; the second, third and fourth columns show the results for BTCUSD, LTCUSD and ETHUSD, respectively

*Contrarian effect detected

The overall results are summarized in Table 2 (for positive abnormal returns) and Table 3 (for negative abnormal returns).

As can be seen, in most cases a strong momentum effect is detected on the day of the abnormal returns both for the positive and negative abnormal returns. This might appear to be obvious since we have analyzed extreme price changes during a day. But it is noteworthy that abnormal returns are detected not at the end of the day, but during the day (the size of current daily return exceeds the abnormal returns benchmark). Since we have found that prices tend to move in the direction of abnormal returns till the end of the day, this means that traders have sufficient time to exploit these patterns by opening a position in the direction of the abnormal returns immediately after this is detected. The average timing parameters for this momentum effect are provided in Tables 2 and 3. Another interesting and important finding (which contradicts the classic overreaction hypothesis) is that this momentum effect tends to continue the next day (with only a few exceptions), although it is limited in time. Usually, it takes a few hours for the price to peak. These timing parameters are also provided in Tables 2 and 3 .

Our findings can be summarized as follows:

- hourly returns during the day of positive/negative abnormal returns are significantly higher/lower than those during the average positive/negative day, i.e., $\mathrm{H} 1$ cannot be rejected; 
Table 3 Overall results for the case of negative abnormal returns

\begin{tabular}{|c|c|c|c|}
\hline Parameter/instrument & BTCUSD & LTCUSD & ETHUSD \\
\hline \multicolumn{4}{|c|}{ Day of the abnormal returns } \\
\hline $\begin{array}{l}\text { Are there significant } \\
\text { differences in returns } \\
\text { (abnormal day vs } \\
\text { usual day)? }\end{array}$ & Yes & Yes & Yes \\
\hline $\begin{array}{l}\text { Any patterns in } \\
\text { cumulative abnormal } \\
\text { returns dynamics? }\end{array}$ & $\begin{array}{l}\text { Yes. CAR decrease till } \\
\text { the end of the day }\end{array}$ & $\begin{array}{l}\text { Yes. CAR decrease till } \\
\text { the end of the day }\end{array}$ & $\begin{array}{l}\text { Yes. CAR decrease till } \\
\text { the end of the day }\end{array}$ \\
\hline $\begin{array}{l}\text { Timing of abnormal } \\
\text { returns }\end{array}$ & $16: 00$ & $14: 00$ & 13:00 \\
\hline \multicolumn{4}{|c|}{ Day after the abnormal returns } \\
\hline $\begin{array}{l}\text { Is there momentum } \\
\text { effect on the day } \\
\text { after the abnormal } \\
\text { returns? }\end{array}$ & Yes & Yes & No \\
\hline $\begin{array}{l}\text { Timing parameters of } \\
\text { momentum } \\
\text { movements }\end{array}$ & $\begin{array}{l}\text { Since the start of the } \\
\text { day till } 11: 00\end{array}$ & $\begin{array}{l}\text { Since the start of the } \\
\text { day till 10:00 }\end{array}$ & $\begin{array}{l}\text { Since the start of the } \\
\text { day till the end of the } \\
\text { day* }\end{array}$ \\
\hline
\end{tabular}

This table presents the overall results for the case of negative abnormal returns. The first column reports the considered parameters; the second, third and fourth columns show the results for BTCUSD, LTCUSD and ETHUSD, respectively

*Contrarian effect detected

- abnormal returns can be detected before the day ends and specific timing parameters for the abnormal returns can be estimated;

- prices tend to move in the direction of abnormal returns till the end of the day, i.e., $\mathrm{H} 2$ cannot be rejected, namely there is a momentum effect on days with abnormal returns;

- the behavior of the market after one-day abnormal returns in most cases also confirms the existence of a momentum effect, i.e., H3 cannot be rejected. Usually, it is shortterm, and specific timing parameters can be estimated for the asset of interest;

- in two cases (BTCUSD positive abnormal returns and ETHUSD negative abnormal returns) a contrarian effect is detected.

On the basis of these results, the following profitable strategies can be developed:

Strategy 1 When it becomes clear that the current day is an abnormal returns day (see the timing of abnormal returns in Tables 2 and 3), a position in the direction of abnormal returns should be opened. This position should then be closed at the end of the day.

Strategy 2 At the beginning of the day after the abnormal returns, a position in the direction of the abnormal returns should be opened. This position should then be closed on the basis of the timing parameters for the momentum effect displayed in Tables 2 and 3. If this effect is not present, a contrarian trading strategy should be used: at the beginning of the day after the abnormal returns a position in the opposite direction to the abnormal returns should be opened. 
Table 4 Trading simulation results for the case of positive abnormal returns

\begin{tabular}{|c|c|c|c|c|c|c|c|c|}
\hline Instrument & $\begin{array}{l}\text { Number } \\
\text { of trades. } \\
\text { units }\end{array}$ & $\begin{array}{l}\text { Number } \\
\text { of suc- } \\
\text { cessful } \\
\text { trades. } \\
\text { units }\end{array}$ & $\begin{array}{l}\text { Number } \\
\text { of suc- } \\
\text { cessful } \\
\text { trades. \% }\end{array}$ & Profit. \% & $\begin{array}{l}\text { Profit \% } \\
\text { per year }\end{array}$ & $\begin{array}{l}\text { Profit } \% \\
\text { per trade }\end{array}$ & $\begin{array}{l}t \text { test cal- } \\
\text { culated } \\
\text { value }\end{array}$ & $\begin{array}{l}t \text { test } \\
\text { status }\end{array}$ \\
\hline \multicolumn{9}{|l|}{ Strategy 1} \\
\hline BTCUSD & 49 & 42 & 86 & 143.11 & 28.62 & 2.92 & 6.62 & Rejected \\
\hline LTCUSD & 38 & 37 & 97 & 311.39 & 103.80 & 8.19 & 7.20 & Rejected \\
\hline ETHUSD & 58 & 45 & 78 & 507.63 & 50.76 & 8.75 & 11.06 & Rejected \\
\hline \multicolumn{9}{|l|}{ Strategy 2} \\
\hline BTCUSD* & 49 & 29 & 59.2 & 75.3 & 15.06 & 1.54 & 1.75 & $\begin{array}{l}\text { Not } \\
\quad \text { rejected }\end{array}$ \\
\hline LTCUSD & 38 & 14 & 37 & 61.80 & 20.60 & 1.63 & 0.76 & $\begin{array}{l}\text { Not } \\
\quad \text { rejected }\end{array}$ \\
\hline ETHUSD & 58 & 25 & 43 & 130.20 & 43.40 & 2.24 & 1.87 & Rejected \\
\hline
\end{tabular}

This table presents the trading simulation results for the case of negative abnormal returns. The first column reports the list of instruments; the second column shows the number of trades in units; the third column provides the number of successful trades in units and the fourth column shows this parameter in \%; the fifth column shows profit generated by trading strategy over the whole period in $\%$; the sixth column shows annual profit in $\%$ and the seventh column provides information about the size of profit per trade; the eighth column reports the value of $\mathrm{t}$ criterion and the ninth shows the $t$ test status: rejected or not rejected *A contrarian trading strategy is used

The trading simulation results for the two strategies for positive abnormal returns are presented in Table 4.

As can be seen, Strategy 1 appears to be highly profitable. The number of successful trades on average is close to $90 \%$ profits per year as well as profits per trade differ across cryptocurrencies but are positive and significant in all cases. The trading simulation results differ from the random ones (as confirmed by the $t$ tests). Strategy 2 is less profitable: the average number of successful trades is less than $50 \%$ and only in 1 out of 3 cases there are statistically significant differences from random trading. Nevertheless, all the simulations generate profits which on an annual basis are much higher than average returns on investment in the USA or other developed countries.

The trading simulation results for the case of negative abnormal returns are presented in Table 5.

The results for Strategy 1 in the case of negative abnormal returns are very similar to those for positive abnormal returns, namely there is a very high percentage of successful trades (on average $85 \%$ ) and significant profits both on an annual and per trade basis. The trading simulations produce statistically significant differences in the results compared with random trading. Strategy 2 is again less profitable (as in the case of positive abnormal returns), but it still "beats the market."

On the whole, the detected anomalies can be exploited in most cases to generate abnormal profits from trading. Using the timing parameters previously calculated, it is possible to generate significant profits from trading in the cryptocurrency market exploiting the momentum effect on the day of the abnormal returns, especially in 
Table 5 Trading simulation results for the case of negative abnormal returns

\begin{tabular}{|c|c|c|c|c|c|c|c|c|}
\hline Instrument & $\begin{array}{l}\text { Number } \\
\text { of trades. } \\
\text { units }\end{array}$ & $\begin{array}{l}\text { Number } \\
\text { of suc- } \\
\text { cessful } \\
\text { trades. } \\
\text { units }\end{array}$ & $\begin{array}{l}\text { Number } \\
\text { of suc- } \\
\text { cessful } \\
\text { trades. \% }\end{array}$ & Profit. \% & $\begin{array}{l}\text { Profit \% } \\
\text { per year }\end{array}$ & $\begin{array}{l}\text { Profit } \% \\
\text { per trade }\end{array}$ & $\begin{array}{l}t \text { test cal- } \\
\text { culated } \\
\text { value }\end{array}$ & $\begin{array}{l}t \text { test } \\
\text { status }\end{array}$ \\
\hline \multicolumn{9}{|l|}{ Strategy 1} \\
\hline BTCUSD & 46 & 42 & 91 & 202.41 & 40.48 & 4.40 & 8.21 & Rejected \\
\hline LTCUSD & 39 & 33 & 85 & 170.75 & 56.92 & 4.38 & 4.31 & Rejected \\
\hline ETHUSD & 57 & 43 & 75 & 334.54 & 111.51 & 5.87 & 7.84 & Rejected \\
\hline \multicolumn{9}{|l|}{ Strategy 2} \\
\hline BTCUSD & 46 & 25 & 54.3 & 52.0 & 10.4 & 1.13 & 1.55 & $\begin{array}{l}\text { Not } \\
\quad \text { rejected }\end{array}$ \\
\hline LTCUSD & 39 & 20 & 51.3 & 75.8 & 25.3 & 1.94 & 1.93 & Rejected \\
\hline ETHUSD* & 57 & 38 & 66.7 & 225.6 & 75.2 & 3.96 & 3.46 & Rejected \\
\hline
\end{tabular}

This table presents trading simulation results for the case of negative abnormal returns. The first column reports the list of instruments; the second column shows the number of trades in units; the third column provides the number of successful trades in units and the fourth column shows this parameter in \%; the fifth column shows profit generated by trading strategy over the whole period in $\%$; the sixth column shows annual profit in $\%$ and the seventh column provides information about the size of profit per trade; the eighth column reports the value of the t-statistic and the ninth shows the outcome of the test (null rejected or not rejected)

*A contrarian trading strategy is used

the case of Strategy 1. Price patterns related to one-day abnormal returns are shortlived. Exploiting the momentum effect on the day after abnormal returns is much less profitable, and the corresponding trading simulations result does not differ from the random trading in half of the cases.

To summarize, these findings suggest that daily abnormal price changes can generate very specific patterns in price behavior; specifically, on the day with abnormal price changes and the following one there is a strong momentum effect. The presence of price patterns and their predictability are inconsistent with the EMH, since these patterns can be the basis for profitable trading strategies that beat the market. (We have shown that the generated results are statistically different from the random trading ones.) This evidence is of interest to practitioners (investors, traders, hedge funds managers, etc.). In the era of high-frequency trading and trading robots, it is increasingly harder to find profit opportunities. Our analysis implies that there might be some in the cryptocurrency market. The same approach could obviously be followed to test such issues in the case of other markets including commodity and stock markets (especially emerging ones), etc. 


\section{Conclusion}

This paper explores the momentum effect in the cryptocurrency market after one-day abnormal returns. Daily and intraday data on the BTCUSD, ETHUSD and LTCUSD exchange rates over the period 01.01.2017-01.09.2019 are analyzed using a number of statistical methods as well as a trading simulation approach. The following hypotheses are tested: (H1) the intraday behavior of hourly returns is different on abnormal returns days compared to normal days; $(\mathrm{H} 2)$ there is a momentum effect on abnormal returns days, and (H3) after one-day abnormal returns.

The results suggest that hourly returns during the day of positive/negative abnormal returns are significantly higher/lower than those during the average positive/negative day. Further, abnormal returns can usually be detected before the day ends by estimating specific timing parameters. Prices tend to move in the direction of the abnormal returns till the end of the day when it occurs, which implies the existence of a momentum effect during that day giving rise to exploitable profit opportunities.

On the basis of these results and the detected price patterns, the following trading strategy is developed: when it becomes clear that the current day is an abnormal returns day, a position in the direction of overreaction should be opened; this position should then be closed at the end of the day. Timing parameters for each of the analyzed assets are calculated. Trading simulation provides evidence of the profitability of this strategy, i.e., the detected anomaly in the cryptocurrency market can be exploited to generate abnormal profits.

A momentum effect (together with profit opportunities) is also observed on the following day. Thus, the following trading strategy is developed: at the beginning of the day after the abnormal returns a position in the direction of the abnormal returns should be opened; this should be closed according to the estimated timing parameters for the momentum effect. If momentum effect is not present (i.e., in the two cases of BTCUSD positive abnormal returns and ETHUSD negative abnormal returns), a contrarian trading strategy should be used: at the beginning of the day after the abnormal returns a position in the opposite direction to the overreaction should be opened. Trading simulations confirm the profitability of these strategies. These findings are of interest to both investors aiming to maximize their profits and academics interested in the empirical relevance of the EMH. Future research could carry out a similar type of investigation in the case of other markets (e.g., commodity and stock markets), especially for the emerging economies.

Acknowledgements The second-named author gratefully acknowledges financial support from the Ministry of Education and Science of Ukraine (0117U003936).

Open Access This article is licensed under a Creative Commons Attribution 4.0 International License, which permits use, sharing, adaptation, distribution and reproduction in any medium or format, as long as you give appropriate credit to the original author(s) and the source, provide a link to the Creative Commons licence, and indicate if changes were made. The images or other third party material in this article are included in the article's Creative Commons licence, unless indicated otherwise in a credit line to the material. If material is not included in the article's Creative Commons licence and your intended use is not permitted by statutory regulation or exceeds the permitted use, you will need to obtain permission directly from the copyright holder. To view a copy of this licence, visit http://creativecommons.org/licenses/by/4.0/. 


\section{References}

Aalborg, H.A., Molnár, P., de Vries, J.E.: What can explain the price, volatility and trading volume of Bitcoin? Finance Res. Lett. 29, 255-265 (2019)

Aiyagari, S.Rao, Gertler, M.: Overreaction of asset prices in general equilibrium. Rev. Econ. Dyn. 2(1), 3-35 (1999)

Barberis, N., Shleifer, A., Vishny, R.W.: A model of investor sentiment. J. Financ. Econ. 49, 307-343 (1998)

Bariviera, A.F.: The inefficiency of Bitcoin revisited: a dynamic approach. Econ. Lett. 161, 1-4 (2017)

Bartos, J.: Does Bitcoin follow the hypothesis of efficient market? Int. J. Econ. Sci. IV(2), 10-23 (2015)

Baytas, A., Cakici, N.: Do markets overreact: international evidence. J Bank Financ. 23, 1121-1144 (1999)

Bouri, E., Lau, C.K.M., Lucey, B., Roubaud, D.: Trading volume and the predictability of return and volatility in the cryptocurrency market. Finance Res. Lett. (2018). https://doi.org/10.1016/j.frl.2018. 08.015

Bremer, M., Sweeney, R.: The reversal of large stock price decreases. J. Finance 46, 747-754 (1991)

Brown, K.C., Harlow, W.V., Tinic, S.M.: Risk aversion, uncertain information, and market efficiency. J. Financ. Econ. 22, 355-385 (1988)

Caporale, G.M., Plastun, A.: The day of the week effect in the cryptocurrency market. Finance Res. Lett. (2018). https://doi.org/10.1016/j.frl.2018.11.012

Caporale, G., Plastun, A.: Price overreactions in the cryptocurrency market. J. Econ. Stud. 46(5), 1137-1155 (2019)

Caporale, G.M., Gil-Alana, L., Plastun, A.: Short-term price overreactions: identification, testing, exploitation. Comput. Econ. 51(4), 913-940 (2018)

Caporale, G.M., Plastun, A., Oliinyk, V.: Bitcoin fluctuations and the frequency of price overreactions. Financ. Mark. Portf. Manag. 33(2), 109-131 (2019)

Chang, R., McLeavey, D., Rhee, S.: Short-term abnormal returns of the contrarian strategy in the Japanese stock market. J. Bus. Financ. Account. 22, 1035-1048 (1995)

Cheung, A., Roca, E., Su, J.-J.: Crypto-currency bubbles: an application of the Phillips-Shi-Yu (2013) methodology on Mt. Gox Bitcoin prices. Appl. Econ. 47, 2348-2358 (2015)

Chevapatrakul, T., Mascia, D.: Detecting overreaction in the Bitcoin market: a quantile autoregression approach. Finance Res. Lett. 30, 371-377 (2019)

Clare, A., Thomas, S.: The overreaction hypothesis and the UK stock market. J. Bus. Financ. Acc. 22, 961-973 (1995)

Clements, A., Drew, M., Reedman, E., Veeraraghavan, M.: The death of the overreaction anomaly? A multifactor explanation of contrarian returns. IMFI 6, 76-85 (2009)

Corbet, S., Lucey, B., Yarovaya, L.: Datestamping the Bitcoin and Ethereum bubbles. Finance Res. Lett. 26, 81-88 (2018)

Cox, D.R., Peterson, D.R.: Stock returns following large one-day declines: evidence on short-term reversals and longer-term performance. J. Finance 49, 255-267 (1994)

Cutler, D., Poterba, J., Summers, L.: Speculative dynamics. Rev. Econ. Stud. 58, 529-546 (1991)

Daniel, K., Hirshleifer, D., Subrahmanyam, A.: Investor psychology and security market under- and overreactions. J. Financ. 53, 1839-1886 (1998)

Duran, A., Caginalp, G.: Overreaction diamonds: precursors and aftershocks for significant price changes. Quant. Financ. 7(3), 321-342 (2007)

De Bondt, W., Thaler, R.: Does the stock market overreact? J. Finance 40, 793-808 (1985)

Ferri, M., Min, C.: Evidence that the stock market overreacts and adjusts. J. Portf. Manag. 22, 71-76 (1996)

Giannetti, A., Larson, S., Lee, C., Madura, J.: Price movements, information, and liquidity in the night trading market. Financ. Rev. 41(1), 119-137 (2006)

Govindaraj, S., Livnat, J., Savor, P., Zhaoe, C.: Large price changes and subsequent returns. J. Invest. Manag. 12(3), 31-58 (2014)

Griffin, D., Tversky, A.: The weighing of evidence and the determinants of confidence. Cogn. Psychol. 24, 411-435 (1992)

Halaburda, H., Gandal, N.: Competition in the cryptocurrency market. NET Institute Working Paper No. 14-17. SSRN: https://ssrn.com/abstract=2506463 or http://dx.doi.org/10.2139/ssrn.2506463 (2014)

Hong, H., Stein, J.C.: A unified theory of underreaction, momentum trading and overreaction in asset markets. J. Finance 54, 2143-2184 (1999)

Jegadeesh, N., Titman, S.: Returns to buying winners and selling losers: implications for stock market efficiency. J. Finance 48, 65-91 (1993) 
Kocenda, E., Moravcová, M.: Intraday effect of news on emerging european forex markets: intraday effect of news on emerging European forex markets. Econ. Syst. 42(4), 597-615 (2018)

Kosc, K., Sakowski, P., Slepaczuk, R.: Momentum and contrarian effects on the cryptocurrency market. Phys. A (2019). https://doi.org/10.1016/j.physa.2019.02.057

Kryzanowski, L., Zhang, H.: The contrarian strategy does not work in Canadian markets. J. Financ. Quant. Anal. 27, 383-395 (1992)

Kurihara, Y., Fukushima, A.: The market efficiency of Bitcoin: a weekly anomaly perspective. J. Appl. Finance Bank. 7(3), 57-64 (2017)

Larson, S., Madura, J.: What drives stock price behavior following extreme one-day returns. J. Financ. Res. South. Financ. Assoc. 26, 113-127 (2003)

Lasfer, M., Melnik, A., Thomas, D.: Short-term reaction of stock markets in stressful circumstances. J. Bank. Finance 27(10), 1959-1977 (2003)

Lehmann, B.: Fads, martingales, and market efficiency. Q. J. Econ. 105, 1-28 (1990)

Lobe, S., Rieks, J.: Short-term market overreaction on the Frankfurt stock exchange. Q. Rev. Econ. Finance 51(2), 113-123 (2010)

MacKinlay, A.C., Richardson, M.: Using generalized method of moments to test mean-variance efficiency. J. Financ. 46, 511-527 (1991)

Madura, J., Richie, N.: Overreaction of exchange traded funds during the bubble of 1998-2002. J. Behav. Finance 5(2), 91-104 (2004)

Mynhardt, R.H., Plastun, A.: The overreaction hypothesis: the case of Ukrainian stock market. Corpor. Ownership Control 11, 406-423 (2013)

Panagiotis, T., Renatas, K., Bayasgalan, T.: Momentum trading in cryptocurrencies: short-term returns and diversification benefits. Econ. Lett. (2019). https://doi.org/10.1016/j.econlet.2019.108728

Parikakis, G., Syriopoulos, T.: Contrarian strategy and overreaction in foreign exchange markets. Res. Int. Bus. Finance 22, 319-324 (2008)

Poteshman, A.: Underreaction, overreaction and increasing misreaction to information in the options market. J. Finance 56, 851-876 (2001)

Pritamani, M., Singal, V.: Return predictability following large price changes and information releases. J. Bank. Finance 25(4), 631-656 (2001)

Qing, C., Xinyuan, L., Xiaowu, Z.: Cryptocurrency momentum effect: DFA and MF-DFA analysis. Phys. A (2019). https://doi.org/10.1016/j.physa.2019.04.083

Savor, P.: Stock returns after major price shocks: the impact of information. J. Financ. Econ. 106(3), 635-659 (2012)

Schnusenberg, O., Madura, J.: Do US stock market indexes over-or under react? J. Financ. Res. 24(2), 179-204 (2001)

Urquhart, A.: The inefficiency of Bitcoin. Econ. Lett. 148, 80-82 (2016)

Wan, J., Kao, C.: Evidence on the contrarian trading in foreign exchange markets. Econ. Model. 26, 1420-1431 (2009)

Yukun, L., Tsyvinski, A.: Risks and returns of cryptocurrency. Meeting Papers 160, Society for Economic Dynamics (2019)

Publisher's Note Springer Nature remains neutral with regard to jurisdictional claims in published maps and institutional affiliations.

Guglielmo Maria Caporale (M.Sc., Ph.D., LSE) is Professor of Economics and Finance and Director of the Centre for Empirical Finance at Brunel University, London. He is also a Visiting Professor at London South Bank University, a Research Professor at DIW Berlin, a CESifo Research Network Fellow, and an Associate Researcher at the International Laboratory of Financial Economics (LFE), International College of Economics and Finance (ICEF), Higher School of Economics (HSE), Moscow. Prior to taking up his current position, he was a Research Officer at the National Institute of Economic and Social Research in London; a Research Fellow and then a Senior Research Fellow at the Centre for Economic Forecasting at the London Business School; Professor of Economics at the University of East London; Professor of Economics and Finance as well as Director of the Centre for Monetary and Financial 
Economics at London South Bank University. He has numerous publications in a wide range of top academic journals in economics and finance.

Alex Plastun is Professor at the Chair of International Economic Relations in the Sumy State University. Before joining Sumy State University, he was a trader and analyst in several investment companies. He still trades in the different financial markets using his own trading strategies. Professor Plastun tries to use his experience as a trader to inform academic theory and is particularly interested in market inefficiencies. He has published in such outlets as the International Economics, Research in International Business and Finance, Journal of Applied Economics, Finance Research Letters, Journal of Economic Studies, Computational Economics, and many others. Professor Plastun was awarded a PhD in Finance by the Ukrainian Academy of Banking. 